\title{
ESTUDO DE FLUXO SUBTERRÂNEO EM UMA ÁREA EXPERIMENTAL EM PONTAL DO SUL-PR
}

\author{
Groundwater Flow Study in an Experimental Area in Pontal do Sul -PR
}

Rogério Tadeu de Souza ${ }^{1}$ e Thiago Elias Ramos Bonis Silva ${ }^{2}$

\begin{abstract}
RESUMO: $\quad$ Regiões costeiras apresentam uma hidrogeologia bastante complexa, tanto sob o ponto de vista quantitativo como qualitativo. São regiões que apresentam uma correlação muito estreita entre a superfície do aquífero livre, variações de marés e fatores climáticos. Esses fatores, de forma isolada ou associados, levam a uma preocupação quanto a vulnerabilidade desses aquíferos. Este trabalho tem por objetivo realizar uma caracterização completa da hidrogeologia da área de estudo, localizada dentro e adjacente ao Centro de Estudos do Mar (CEM) da Universidade Federal do Paraná (UFPR), através de instalação de piezômetros e poços de monitoramentos os quais permitiram determinar o fluxo subterrâneo e suas interrelações com os fatores climáticos, movimento de maré, dos cálculos dos parâmetros hidrodinâmicos e hidroquímicos. A partir dos dados de monitoramento do nível dágua subterrâneo, índices pluviométricos e comparando-os com os dados obtidos da tábua de marés da Diretoria de Hidrografia e Navegação da Marinha do Brasil, estação de Barra de Paranaguá - Canal da Galheta, verificou-se que a influência da maré no comportamento do fluxo subterrâneo é quase nulo ou praticamente não altera de forma significativa as variações do nível dágua do aquífero livre. Constatou-se que a descarga do aquífero livre dá-se, preferencialmente, em direção ao canal de mangue e não em relação ao mar.
\end{abstract}

Palavras chaves: aquífero livre, água subterrânea, hidrogeologia, áreas costeiras.

ABSTRACT: Coastal regions present quite complex hydrogeology, both in quantitative and qualitative perspectives. These regions present a very closely correlation among unconfined aquifer surface, tidal variations, geological and climatic factors. All these factors, isolated or associated, lead to concern about the vulnerability of these aquifers. The aim of this work is to perform a complete hydrogeology characterization of the site, located inside and also adjacent to the CEM-UFPR (Ocean Study Center, Federal University of Paraná). This characterization contemplated the installation of piezometers and monitoring wells, which determined the groundwater flow and their correlation with climatic factors and tidal movement. Hydrodynamic and hydrochemical parameters were also determined.

By comparing measured groundwater levels and pluviometer rates to data obtained at the Barra de Paranaguá station - Galheta channel, by the Department of Hydrology and Navigation of the Brazilian Navy, it was possible to verify that the tidal influence in the groundwater flow is quite null, neither modifies significantly the unconfined water level. Finally, it was determined that the unconfined aquifer discharge is directed mostly towards the mangrove channel, instead of to the sea.

Key words: unconfined aquifer, groundwater, hydrogeology, coastal areas.

\section{INTRODUÇÃO}

Regiões costeiras apresentam uma hidrogeologia bastante complexa e vulnerável, tanto do ponto de vista quantitativo como qualitativo. São regiões que apresentam uma correlação muito estreita entre o aquífero livre, as variações de marés, a geologia e a pluviosidade. Esses fatores, de forma isolada ou associados, levam a uma preocupação quanto à vulnerabilidade desses aquíferos. Uma boa caracterização hidrogeológica fornece conhecimentos que podem ser utilizados para propiciar uma melhor gestão territorial e dos recursos hídricos subterrâneos.

Visando propiciar um melhor gerenciamento dos recursos hídricos subterrâneos, em Pagasa Island (internacionalmente conhecida como Tithu Island) localizada ao sul do Mar da China e a $500 \mathrm{~km}$ a noroeste de Puerto Princesa City, foi realizada pesquisa parecida á realizada em Pontal do Sul - PR. Ao longo de 24 anos, foram instalados 17 poços para abastecimento de água na ilha com o objetivo de suprir a demanda de água potável para a população local. Destes, 16 poços foram utilizados para monitorar nível d'água, condutividade elétrica e temperatura por 72 horas no perído de 2 a 5 de maio de 1999. A ilha possui geologia predominante composta por areia de origem marinha. A condutividade hidráulica foi determinada através de testes de slug em 2 poços situados na porção leste da ilha. Os valores medidos, $8 \times 10^{-5} \mathrm{~m} / \mathrm{s}$ e $3.9 \times 10^{-4} \mathrm{~m} / \mathrm{s}$, correspondem à permeabilidade encontrada para materiais de granulação de areia grossa a cascalho. Os dados foram correlacionados e analizados com a variação de maré. O estudo apontou grande vulnerabilidade do aquífero principalmente para potenciais contaminações por hidrocarbonetos, áreas para depósitos de lixo, sistemas de esgoto impróprios e intrusão salina por consequente super explotação do aquífero (ONG et. al., 2000). 


\section{ÁREA DE ESTUDO}

A área de estudo localiza-se no município de Pontal do Paraná, litoral do Paraná, distante aproximadamente $120 \mathrm{~km}$ de Curitiba, na localidade denominada Pontal do Sul, onde está instalado o CEM - Centro de Estudos do Mar da Universidade Federal do Paraná (Figura 1). Situa-se na Bacia do Rio Perequê, que faz parte da extensa planície costeira de Paranaguá. Esta área é formada por uma planície de cordões, como é chamada, e possui aproximadamente $7 \mathrm{~km}$ de largura e $50 \mathrm{~km}$ de comprimento, estendendo-se de Pontal do Paraná até a Baía de Guaratuba. Essa parte da zona costeira do Atlântico foi formada pela emersão de uma barreira de acomodação sob condições de baixa elevação do nível do mar. Como resultado, essa área abrange uma densa pilha de sedimentos inconsolidados de origem flúvio-marinha. Esses sedimentos estão relacionados predominantemente ao movimento de transgressão e regressão marinha. A área de estudo é composta por solos de textura essencialmente arenosa (RACHWAL e CURCIO, 2001), sendo a espessura da camada superior do Holoceno de aproximadamente $20 \mathrm{~m}$ e profundidade do embasamento em torno de 100 a $120 \mathrm{~m}$. A planície de cordões é constituída de sulcos paralelos na areia e é largamente composta de grãos de areia de tamanho fino a médio com intercalações de lamas estuarinas em diferentes profundidades (SURESH BABU et al., 2008).

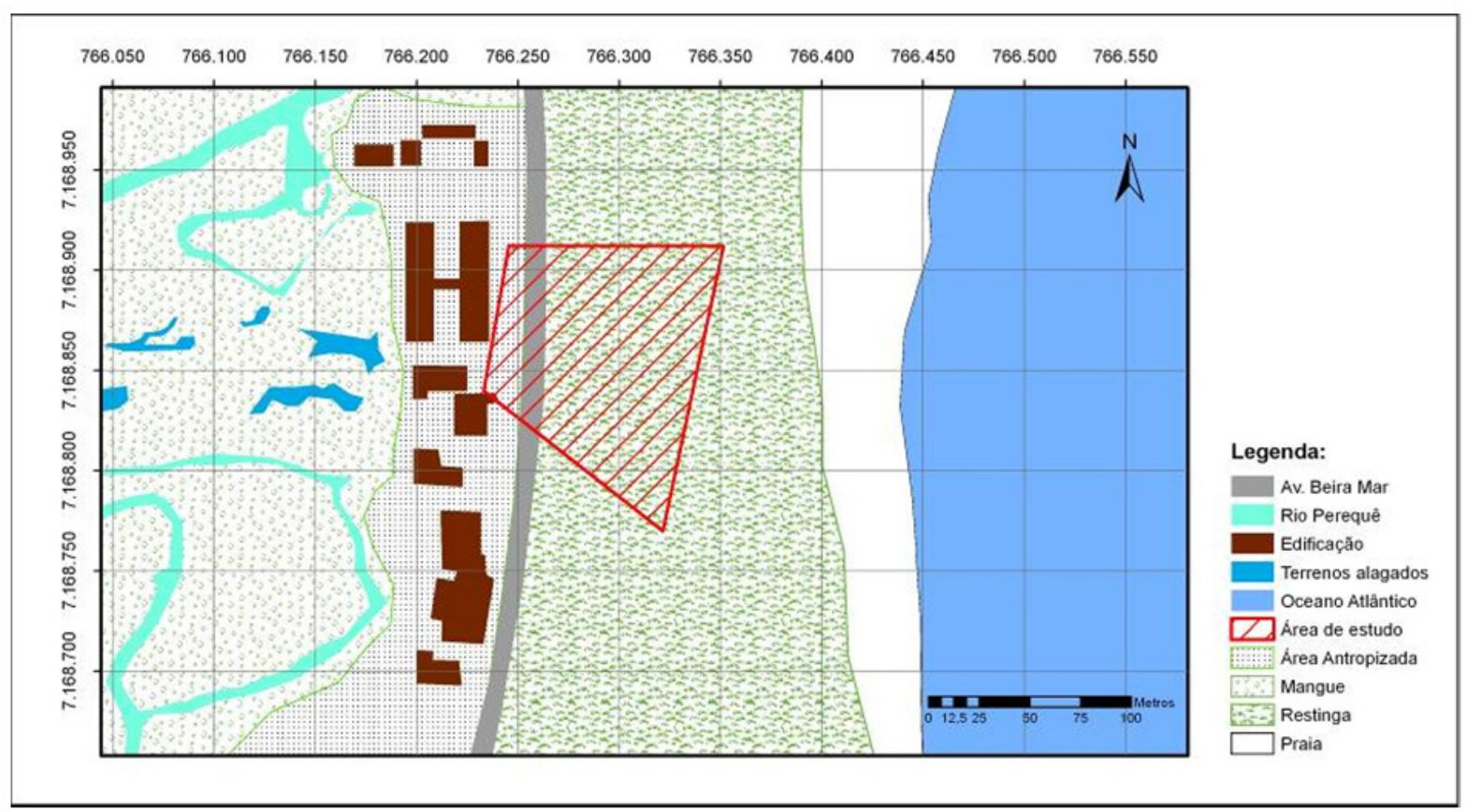

Figura 1: Localização da área de estudo.

Figure 1: Location of the study area.

\section{METODOLOGIA}

A metodologia de trabalho empregada neste estudo compreendeu as seguintes fases. 
Instalação de piezômetros e poços de de monitoramento (Tabela 1), sendo que estes monitoramento instrumentos foram locados de forma a representar

Para a caracterização da hidrogeologia e a totalidade da área estudada. geologia da região, foram instalados cinco poços

Tabela 1: Dados cadastrais dos poços de monitoramento instalados na área de estudo.

Table 1: Registration data of the monitoring wells installed in the study area.

\begin{tabular}{|c|c|c|c|c|c|c|}
\hline Piezômetro & $\begin{array}{c}\text { Perfurado } \\
(\mathbf{m})\end{array}$ & $\begin{array}{c}\text { Cota Boca } \\
(\mathbf{m})\end{array}$ & $\begin{array}{c}\text { Instalado } \\
(\mathbf{m})\end{array}$ & $\begin{array}{c}\text { Filtro } \\
(\mathbf{m})\end{array}$ & $\begin{array}{c}\text { Revestimento } \\
(\mathbf{m})\end{array}$ & $\begin{array}{c}\text { N.A. } \\
(\mathbf{m})\end{array}$ \\
\hline PCH 01 & 2,05 & 0,115 & 1,87 & 0,80 & 1,07 & 1,23 \\
\hline PCH 02 & 1,98 & 0,130 & 1,78 & 0,80 & 0,98 & 0,95 \\
\hline PCH 03 & 2,63 & 0,080 & 2,43 & 0,80 & 1,63 & 1,85 \\
\hline PCH 04 & 2,17 & 0,090 & 2,05 & 0,80 & 1,25 & 1,48 \\
\hline PCH 05 & 1,62 & 0,080 & 1,49 & 0,80 & 0,69 & 0,87 \\
\hline
\end{tabular}

Devido ao tipo de solo a ser perfurado (areia) e também a pouca profundidade no nível d'água do aquífero livre, não superior a 1,50 m, optou-se pelo trado manual durante a perfuração para instalação dos piezômetros. A perfuração foi realizada em diâmetro de 4", enquanto que o piezômetro foi construído com tubo PVC de 2" de diâmetro. Os tubos filtro apresentam abertura das ranhuras entre 0,2 a $0,5 \mathrm{~mm}$, confeccionadas manualmente por meio de serra de aço. Não foi utilizado pré-filtro durante a construção dos piezômetros, uma vez que o meio é composto por areias de grãos bem selecionados. A Figura 2 mostra a localização dos piezômetros instalados.

Durante a perfuração para instalação dos poços de monitoramento foi utilizado o trado manual de 4" até a profundidade em que se encontrava o nível d'água do aquífero livre, a partir daí, utilizou-se um equipamento desenvolvido especialmente para a perfuração. Esse equipamento conjuga o método de percussão com a lavagem do furo com água da própria formação aquífera, e consiste em um tubo de aço de 4" de diâmetro e aproximadamente 0,70 metros de comprimento, uma esfera e uma haste metálica, sustentados por uma corda de náilon que permitia o movimento de percussão e a retirada do material que ficava retido dentro do tubo metálico devido ao avanço da perfuração.

Para dar sustentabilidade à parede do furo durante a perfuração foi utilizado um tubo de revestimento de $100 \mathrm{~mm}$ que era retirado após a instalação do poço de monitoramento.

Foram instalados 03 poços na área de estudo (Tabela 2), que serviram para monitoramento das leituras do nível d'água. Estes poços foram construídos com tubo de PVC de 2", com ranhuras com aberturas entre 0,2 e $0,5 \mathrm{~mm}$. Ao contrário dos piezômetros, durante a instalação dos poços de monitoramento, optou-se pelo utilização de pré-filtro constituído de areia selecionada arestada de 1,0 a 2,0 mm de diâmetro. Dois destes poços de monitoramento estão localizados a $0,20 \mathrm{~m}$ dos piezômetros $\mathrm{PCH} 01$ e $\mathrm{PCH} 04$ e o terceiro está localizado na área de restinga. 


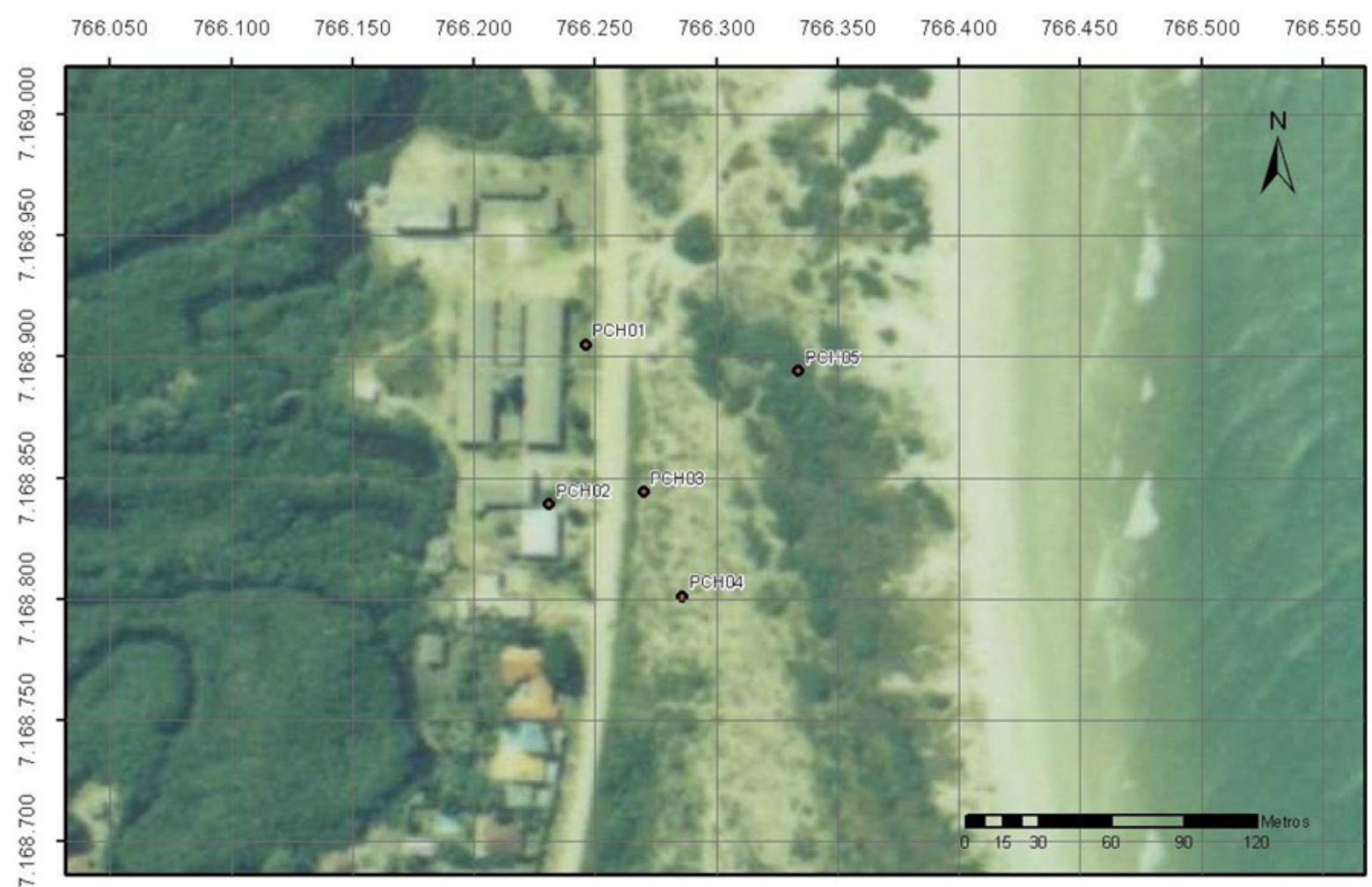

Figura 2: Localização dos piezômetros para caracterização hidrogeológica e geológica.

Figure 2: Piezometer location to the hydrogeologic and geologic characterization.

Tabela 2: Dados cadastrais dos piezômetros instalados na área de estudo.

Table 2: Reference data for the piezometers installed in the study area.

\begin{tabular}{|c|c|c|c|c|c|c|c|c|}
\hline Poço & $\begin{array}{c}\text { Perfurado } \\
(\mathbf{m})\end{array}$ & $\begin{array}{c}\text { Coordenadas } \\
\text { UTM }\end{array}$ & $\begin{array}{c}\text { Diâmetro } \\
\text { Revestimento } \\
(\mathbf{m m})\end{array}$ & $\begin{array}{c}\text { Cota } \\
\text { Boca }(\mathbf{m})\end{array}$ & $\begin{array}{c}\text { Instalado } \\
(\mathbf{m})\end{array}$ & $\begin{array}{c}\text { Filtro } \\
(\mathbf{m})\end{array}$ & $\begin{array}{c}\text { Diâmetro do } \\
\text { poço (mm) }\end{array}$ & $\begin{array}{c}\text { N.A. } \\
(\mathbf{m})\end{array}$ \\
\hline PMCH 01 & 3,75 & $\begin{array}{c}766246 \mathrm{E} \\
7168905 \mathrm{~N}\end{array}$ & 100 & 0,115 & 2,96 & 2,50 & 50 & $1,20^{*}$ \\
\hline $\begin{array}{c}\text { PMCH } \\
\text { 04-A }\end{array}$ & 3,75 & $\begin{array}{c}766286 \mathrm{E} \\
7168801 \mathrm{~N}\end{array}$ & 100 & 0,090 & 2,91 & 2,20 & 50 & $1,42^{* *}$ \\
\hline $\begin{array}{c}\text { PMCH } \\
\text { 44-B }\end{array}$ & 3,75 & $\begin{array}{c}766286 \mathrm{E} \\
7168801 \mathrm{~N}\end{array}$ & 100 & 0,090 & 3,12 & 2,20 & 50 & $1,43^{* * *}$ \\
\hline
\end{tabular}

$* 04 / 10 / 2009-16: 00 h s, * * 04 / 10 / 2009-17: 15 h s, * * * 05 / 10 / 2009-17: 00 h s$.

\section{Levantamento topográfico}

Para determinação da cota dos piezômetros, objetivando a elaboração do mapa potenciométrico, optou-se pelo método de nivelamento geométrico, considerado esse o método mais preciso entre os tipos de nivelamento e especialmente pela área de estudo se tratar de uma planície costeira com baixas variações topográficas. Para tal nivelamento foi utilizado um nível da marca LEICA, modelo NA 820, e uma mira de alumínio, sendo que o datum utilizado como referência corresponde a um ponto de cota conhecida, RN da Portobrás, $(1,977$ 
m.s.n.m.) localizado no CEM, nas coordenadas Latitude $-25^{\circ} 34^{\prime} 22,9582^{\prime \prime}$ e Longitude $-48^{\circ} 21^{\prime}$ 00,1065 " WGS-84. As cotas obtidas a partir do nivelamento geométrico foram aferidas através de uma estação total da marca LEICA, modelo TC407.

\section{Análise granulométrica}

Durante a perfuração do piezômetro $\mathrm{PCH} 03$ foram coletadas amostras do material perfurado em quatro diferentes profundidades: 0,0 a 0,6 metros; 1,0 a 1,4 metros; 1,6 a 2,0 metros; e 2,0 a 2,4 metros.

Foram realizados ensaios de granulometria nestas amostras e, posteriormente, elas foram analisadas segundo a norma ABNT NBR 6502/95, que estabelece a classificação do solo segundo sua granulometria.

\section{Determinação da condutividade hidráulica}

A condutividade hidráulica foi determinada por dois métodos distintos: pelo ensaio de permeabilidade em nível variável e pela curva granulométrica.

O ensaio de permeabilidade em nível variável (zona saturada), também conhecido como teste de "slug", consiste em introduzir ou retirar um cilindro sólido (slug) dentro de um poço de monitoramento de pequeno diâmetro, de forma que o nível d'água no poço seja elevado ou rebaixado quase instantaneamente (PEDE, 2004), seguido do monitoramento da recuperação do nível neste poço. Os ensaios foram realizados nos piezômetros $\mathrm{PCH} 01, \mathrm{PCH} 02$ e $\mathrm{PCH} 05$, e a interpretação dos dados foi realizada por meio software Winslug ${ }^{\circledR}(\mathrm{CHANG}$ e CARRIER, 2000), utilizando-se do método de Hvorslev (1951).

A condutividade hidráulica também foi determinada pela distribuição da curva granulométrica das amostras coletadas durante a perfuração do piezômetro $\mathrm{PCH} 03$. Esta determinação foi realizada através do método Shepherd (1989), onde, de acordo com o tamanho dos grãos, é possível calcular a condutividade hidráulica pela seguinte fórmula:

$$
\mathrm{K}=\mathrm{C} \cdot \mathrm{d}_{50}{ }^{\mathrm{j}} \text {, }
$$

onde: $\mathrm{K}=$ Condutividade hidráulica, em $\mathrm{cm} / \mathrm{s}$; $\mathrm{C}=$ fator de ajuste (obtido experimentalmente); $\mathrm{d}_{50}$ = diâmetro efetivo do grão, em $\mathrm{mm} ; \mathrm{e} \mathrm{j}=$ expoente obtido experimentalmente e está relacionado à textura dos sedimentos.

\section{Coletas e análises hidroquímicas}

Foram coletadas amostras de água nos piezômetros $\mathrm{PCH} 01, \mathrm{PCH} 02, \mathrm{PCH0} 4$ e $\mathrm{PCH} 05$, para análises "in situ" de condutividade elétrica, potencial redox, temperatura e $\mathrm{pH}$. Somente as amostras do piezômetro $\mathrm{PCH} 01$ foram enviadas ao laboratório para análise dos íons maiores normalmente encontrados nas águas subterrâneas (FEITOSA et al., 2008) sendo eles bicarbonato, sulfato, cloreto, cálcio, magnésio e sódio. Estes parâmetros analisados permitiram a caracterização hidroquímica básica das águas subterrâneas relacionadas ao aquífero livre da região, assim como permitiu indicar a origem destas águas a partir das relações iônicas.

Antes da amostragem nos piezômetros foi realizada a purga dos mesmos, onde objetivouse garantir que as amostras de água subterrânea fossem representativas da formação aquífera. $\mathrm{O}$ método adotado para a purga dos piezômetros foi ASTM Standard D 6452 (ASTM, 2008) e o equipamento utilizado é mostrado na Foto 1.

A amostragem de água subterrânea, seja para análise dos parâmetros "in situ" ou laboratoriais, foi realizada utilizando-se de bailers de PVC de $32 \mathrm{~mm}$, sendo um bailer para cada piezômetro, evitando dessa forma a contaminação cruzada.

$\mathrm{O}$ critério de seleção do método de purga e amostragem utilizados levou em consideração a exatidão e precisão necessárias para o objetivo do trabalho, além da fácil operacionalidade para se trabalhar em condições de campo. 


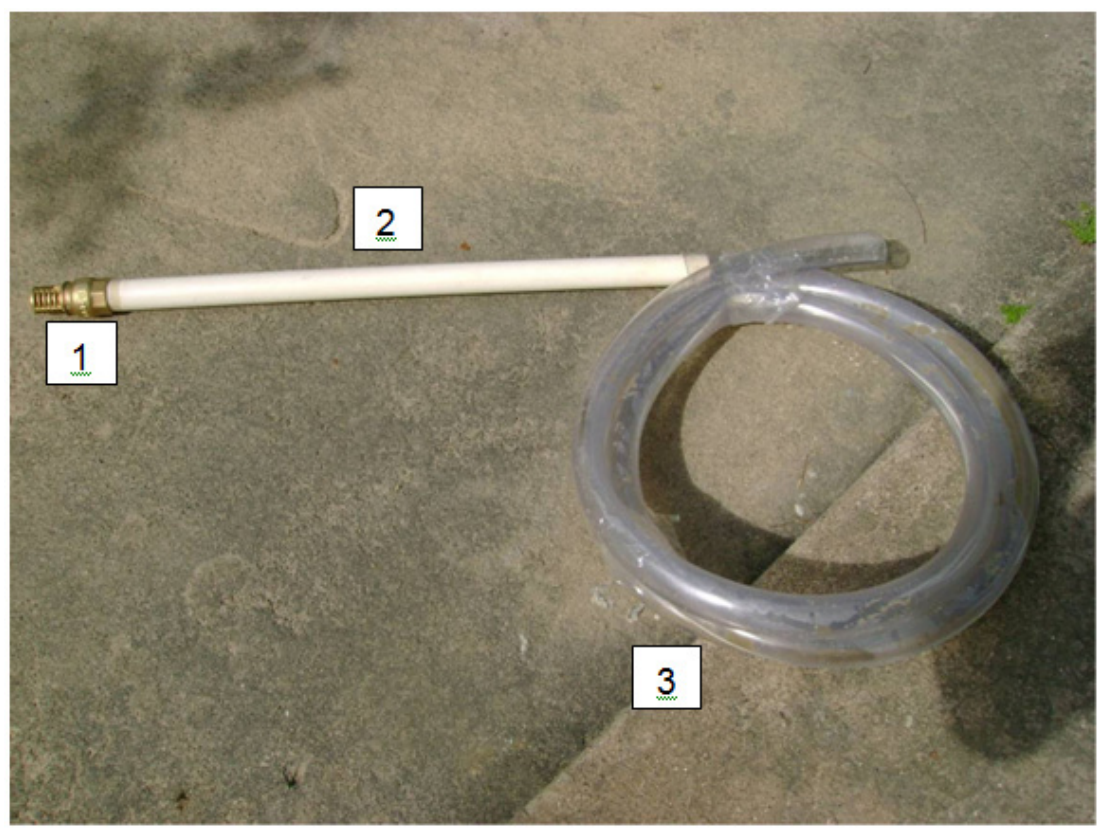

Foto 1: Equipamento construído para purga dos piezômetros. (1) válvula de sucção, (2) tubo de PVC e (3) mangueira de polietileno.

Para análise "in situ" do potencial redox (ORP) foi utilizado um equipamento portátil da marca HANNA Instruments, modelo HI 98120, enquanto que, para a análise da condutividade elétrica, temperatura e $\mathrm{pH}$, também utilizou-se um equipamento da marca HANNA Instruments, modelo HI 98129. Antes das análises, o leitor de condutividade elétrica e $\mathrm{pH}$ foi calibrado com soluções tampão e o medidor de potencial redox foi avaliado com solução padrão de $228 \mathrm{mv}$ com o objetivo de testar a confiabilidade do equipamento.

As amostras de água subterrânea coletadas para análise dos íons maiores foram coletadas após a purga do piezômetro $\mathrm{PCH} 01$, acondicionadas em frascos de PVC, mantidas resfriadas a temperaturas inferiores a $4^{\circ} \mathrm{C}$ e enviadas ao Laboratório de Pesquisas Hidrogeológicas (LPH) da Universidade Federal do Paraná em um prazo máximo de 24 horas após a realização da coleta.

\section{Monitoramento do nível d'água}

Quando da instalação dos piezômetros foram realizadas medições do nível d'água que permitiram a posterior elaboração dos mapas potenciométricos da área. Estas medidas foram realizadas através de medidor de nível d'água eletro-sonoro, dotado de fita métrica, da marca Heron Instruments modelo Dipper-T Water Level Meter.

Com o objetivo de se obter um maior e mais preciso número de medições de nível d'água, que permitisse acompanhamento de todas as fases da lua e marés, no período de 06.10.2009 a 09.11.2009 foi instalado um transdutor de pressão no poço de monitoramento $\mathrm{PMCH01}$ programado para realizar leituras em intervalos de 5 cinco minutos. Nesse período foram realizadas um total 9771 leituras de pressão através de um Mini-Diver ${ }^{\circledR}$ Modelo DI 501 e interpretadas através do software Diver-Office 2008®. Este Mini-Diver foi instalado no dia 06.10.2009 a uma profundidade de 2,30 metros e com uma coluna de nível d'água de 1,02 metros. Todas as leituras de nível d'água foram compensadas através de outro equipamento denominado Baro-Diver ${ }^{\circledR}$, que também permaneceu dentro do poço durante todo o período monitorado, a uma profundidade de 0,745 metros. Estas leituras permitiram calibrar o nível d'água com a pressão atmosférica. Vale ressaltar que também foram realizadas pelo MiniDiver medidas de temperatura concomitantemente às medidas de pressão. Com essas medidas foram realizados estudos correlacionando as elevações de maré com as elevações do nível d'água.

\section{RESULTADOS E DISCUSSÕES}

Os resultados das análises granulométricas das amostas coletadas durante a perfuração do piezômetro PCH03 mostram que os sedimentos, de uma maneira geral, são compostos por grãos de granulação fina a média (Figura 3), e a semelhança entre as curvas granulométricas geradas para essas amostras comprovam a homogeneidade do meio. Durante a análise destes sedimentos foi possível ainda concluir que eles são constituídos basicamente de quartzo, com pouca ou quase nenhuma presença de bioclastos. 


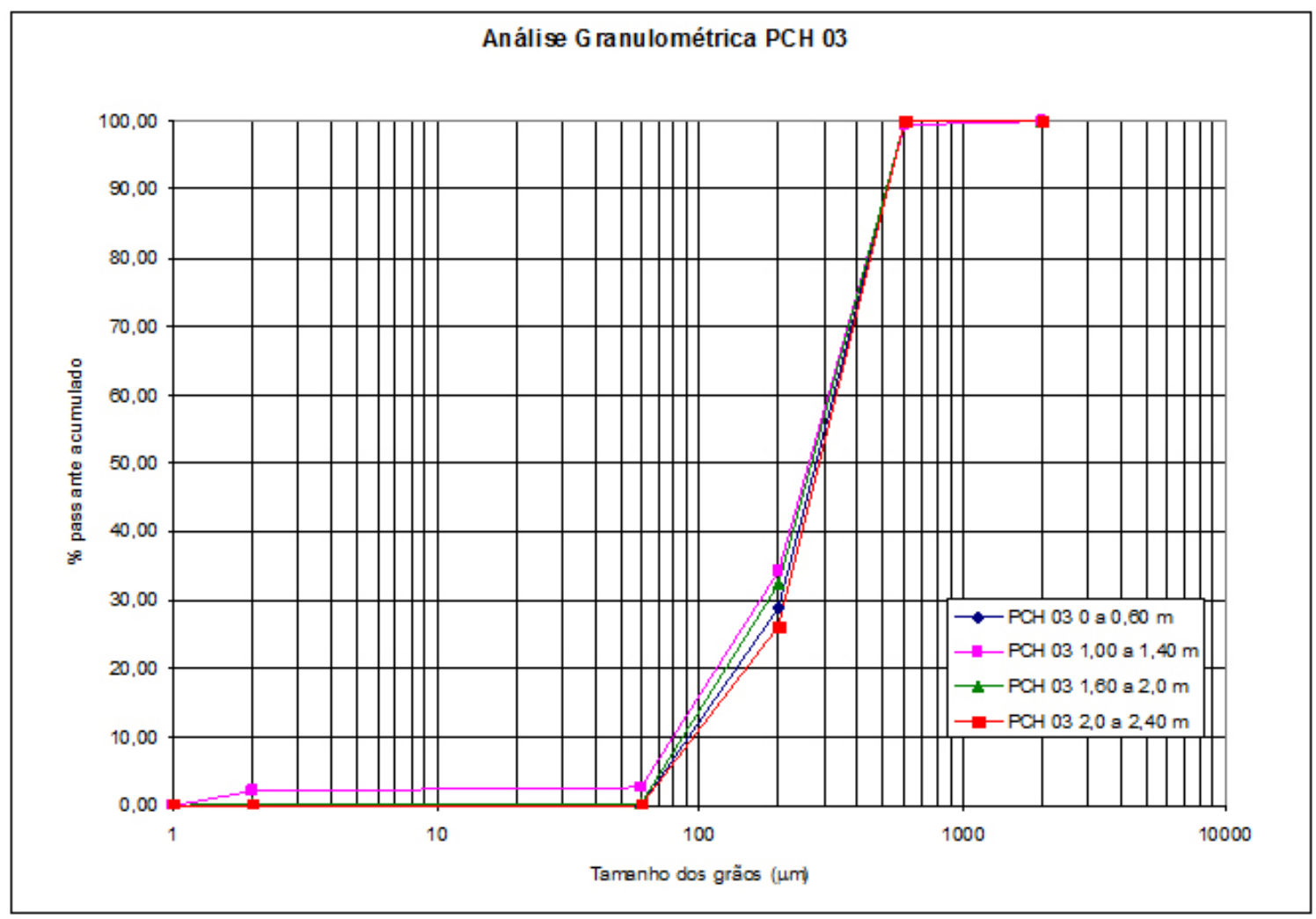

Figura 3: Curvas granulométricas das amostras coletadas na perfuração do piezômetro PCH03.

Figure 3: Granulometric curves of the samples collected during the drilling of piezometer PCHO3.

A condutividade hidráulica foi calculada inicialmente pelo método de Sheperd (1989) utilizando-se das análises granulométricas realizadas. Para o cálculo considerou-se como parâmetro de seleção grãos de textura matura, originários de depósitos de praia, com $\mathrm{C}=1600$ e $\mathrm{j}=1,75$ (SOUZA, 2010). A Tabela 3 apresenta as condutividades hidráulicas obtidas para as amostras coletadas durante a perfuração do piezômetro PCH03.

Tabela 3: Resultados de condutividade hidráulica aplicando o método de Sheperd.

Table 3: Hydraulic conductivity results applying Sheperd method.

\begin{tabular}{|c|c|}
\hline $\begin{array}{c}\text { Profundidade das } \\
\text { amostras }\end{array}$ & $\begin{array}{c}\text { Condutividade } \\
\text { hidráulica }(\mathbf{c m} / \mathbf{s})\end{array}$ \\
\hline $0,00-0,60$ & $6 \times 10^{-2}$ \\
\hline $1,00-1,40$ & $5 \times 10^{-2}$ \\
\hline $1,60-2,00$ & $5 \times 10^{-2}$ \\
\hline $2,00-2,40$ & $6 \times 10^{-2}$ \\
\hline
\end{tabular}

Os testes de slug para determinação da condutividade hidráulica foram realizados em três piezômetros, dois deles localizados na área do CEM - Centro de Estudos do Mar (PCH01 e PCH02) e um localizado na área de restinga (PCH05). Embora tenha sido determinada a condutividade hidráulica pelo método de Sheperd no piezômetro $\mathrm{PCH03,} \mathrm{não} \mathrm{foi} \mathrm{possível} \mathrm{realizar}$ o teste de slug neste instrumento devido a sua localização.

A não utilização de pré-filtro possibilitou uma equalização do nível d'água desde o início do teste, mostrando uma reta de inclinação mais suave, indicando que a coluna de filtro permaneceu totalmente saturada durante o ensaio havendo somente o controle do aquífero. Geralmente, descartam-se os dados gerados no início dos testes (retas de inclinação acentuada no início do gráfico) pelo fato de representarem a drenança do pré-filtro. A Figura 4 mostra os dados gerados no teste de slug realizado no piezômetro $\mathrm{PCH} 05$, juntamente com a reta utilizada durante a interpretação. 


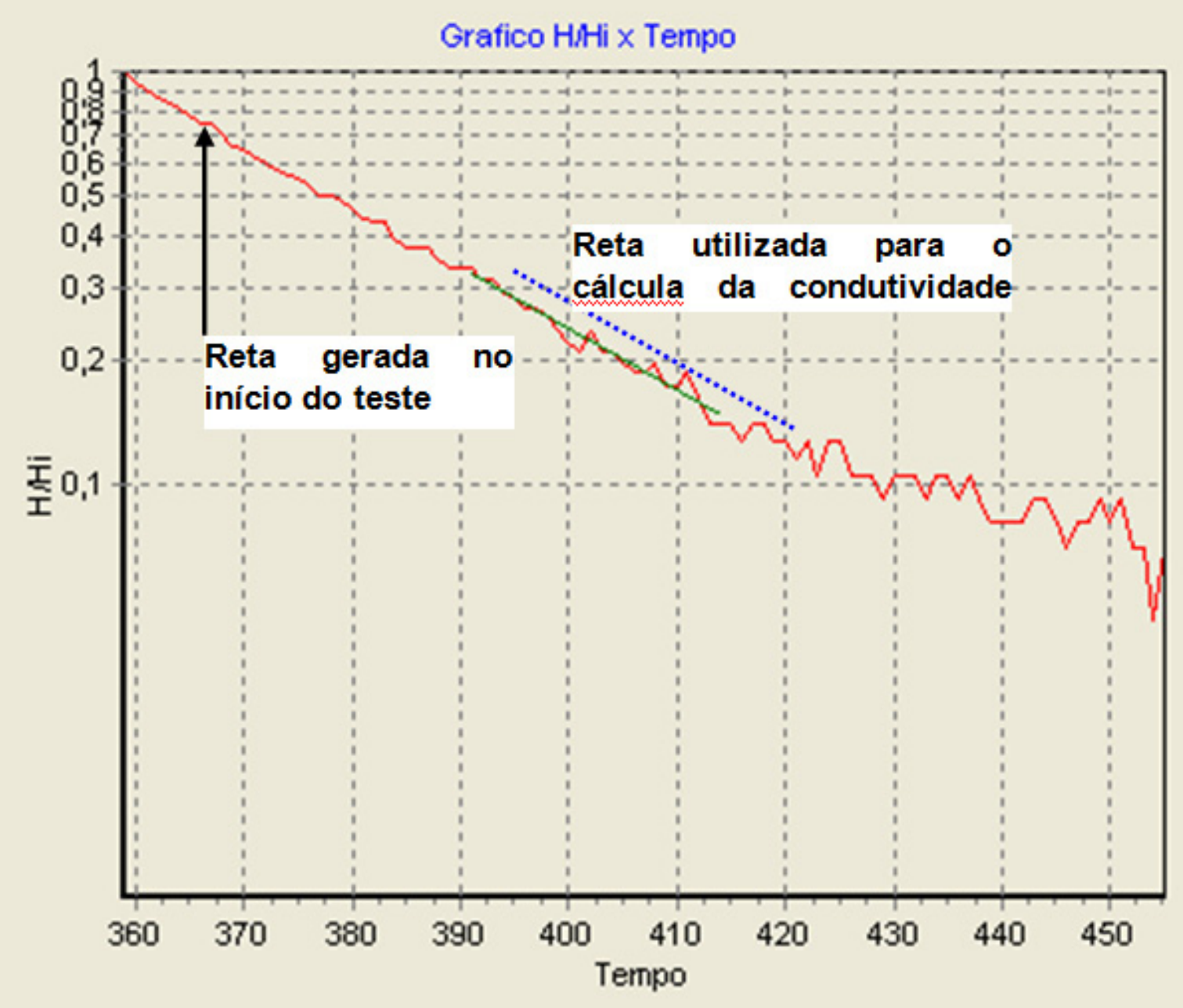

Figura 4: Teste de slug realizado no piezômetro PCH05 mostrando as retas de interpretação.

Figure 4: Slug test accomplished in the piezometer PCH05 showing the interpretation straight line.

Os resultados obtidos pelos testes de slug em todos os piezômetros são apresentados na Tabela 4.

Tabela 4: Resultados de condutividade hidráulica aplicando o teste de slug Table 4: Hydraulic conductivity results applying slug test.

\begin{tabular}{|c|c|}
\hline Piezômetro & $\begin{array}{c}\text { Condutividade } \\
\text { hidráulica }(\mathbf{c m} / \mathbf{s})\end{array}$ \\
\hline PCH 01 & $3,0 \times 10^{-3}$ \\
\hline PCH 02 & $2,0 \times 10^{-3}$ \\
\hline PCH 05 & $7,0 \times 10^{-3}$ \\
\hline
\end{tabular}


Quando comparados os resultados obtidos pelo método de Sheperd com os obtidos pelo teste slug, vemos que o primeiro método resultou em valores de condutividade hidráulica com diferença de uma ordem de grandeza (para mais) em relação ao segundo método utilizado.

O método de Sheperd utiliza fatores de ajustes obtidos experimentalmente para o cálculo da condutividade hidráulica, o que faz com que os resultados sejam menos precisos quando comparados com os resultados obtidos por ensaios de permeabilidade em nível variável (teste de slug). Embora os valores obtidos pelos dois métodos se diferenciem em uma ordem de grandeza, ambos os resultados encontram-se dentro do intervalo estabelecido na literatura.

Embora a análise granulométrica indique que o meio é homogêneo, é possível que ocorram variações locais na granulometria dos sedimentos e consequentemente uma variação entre as condutividades hidráulicas quando comparados em piezômetros diferentes.

Com relação à caracterização hidroquímica, a Tabela 5 apresenta os resultados obtidos para os parâmetros medidos em campo. De acordo com estes parâmetros, as águas subterrâneas do aquífero livre se caracterizam por apresentar baixa mineralização, com condutividade elétrica inferior a $350 \mu \mathrm{s} / \mathrm{cm}$. O Eh encontra-se normalmente acima de $80 \mathrm{mV}$, sugerindo assim um ambiente oxidante, embora na amostra do $\mathrm{PCH0} 4$ este valor esteja próximo de $20 \mathrm{mV}$ indicando uma tendência redutora para o ambiente. No que diz respeito ao $\mathrm{pH}$, todas as amostras apresentaram caráter praticamente neutro, sendo que apenas a amostra PCH 04 destacou-se das demais com $\mathrm{pH}$ levemente básico. Os valores de temperatura da água subterrânea praticamente não variam, apresentando assim uma média de $27^{\circ} \mathrm{C}$ para todas as amostras.

Tabela 5: Resultados das análises de água realizadas "in situ"

Table 5: "In situ" water chemistry analysis results.

\begin{tabular}{|c|c|c|c|c|}
\hline $\begin{array}{c}\text { Parâmetro } \\
\text { Analisado }\end{array}$ & $\begin{array}{c}\text { PCH } \\
\mathbf{0 1}\end{array}$ & $\begin{array}{c}\text { PCH } \\
\mathbf{0 2}\end{array}$ & $\begin{array}{c}\text { PCH } \\
\mathbf{0 4}\end{array}$ & $\begin{array}{c}\text { PCH } \\
\mathbf{0 5}\end{array}$ \\
\hline C.E. $(\mu \mathrm{s} / \mathrm{cm})$ & 159 & 150 & 117 & 323 \\
\hline Eh $(\mathrm{mV})$ & 97 & 89 & 23 & 84 \\
\hline Temperatura $\left({ }^{\circ} \mathrm{C}\right)$ & 27,6 & 26,2 & 26,9 & 27,7 \\
\hline $\mathrm{pH}$ & 6,95 & 6,15 & 7,95 & 6,8 \\
\hline
\end{tabular}

Devido à homogeneidade do aquífero livre, juntamente com a proximidade dos pontos de amostragem, era de se esperar que eles apresentassem valores semelhantes para os parâmetros medidos "in situ". Entretanto, foram observadas diferenças significativas no $\mathrm{pH}$ e potencial redox da amostra do piezômetro $\mathrm{PCH} 04$ o que não pode ser explicado pelos métodos utilizados neste estudo. A maior condutividade elétrica observada no piezômetro PCH05 seria resultado da maior proximidade deste instrumento com o mar o que favorece um incremento na sua salinidade.

Foi coletada amostra no piezômetro PCH01 para análise em laboratório dos íons maiores normalmente encontrados nas águas subterrâneas. Uma forma de verificar a consistência dos resultados é através do balanço iônico, ou seja, a soma do miliequivalentes dos cátions deve ser igual a soma dos miliequivalentes de ânions. $\mathrm{O}$ erro obtido pelo balanço iônico foi de 9,36\%, considerado aceitável segundo Custódio e Llamas (2001), onde consideram-se aceitáveis erros inferiores a $10 \%$ para aquelas amostras com condutividade elétrica entre 50 e $200 \mu \mathrm{s} / \mathrm{cm}$.

Os valores de concentração de cálcio, magnésio, sódio, cloreto, sulfato e bicarbonato foram tratados e representados no diagrama de 
Stiff (Figura 5) com a finalidade de caracterizar e classificar a amostra. De acordo com a análise, a amostra do piezômetro $\mathrm{PCH} 01$ corresponde a uma água bicarbonatada-cálcica-sódica com baixa influência de águas marinhas evidênciada pelas baixas concentrações de sódio e cloreto.

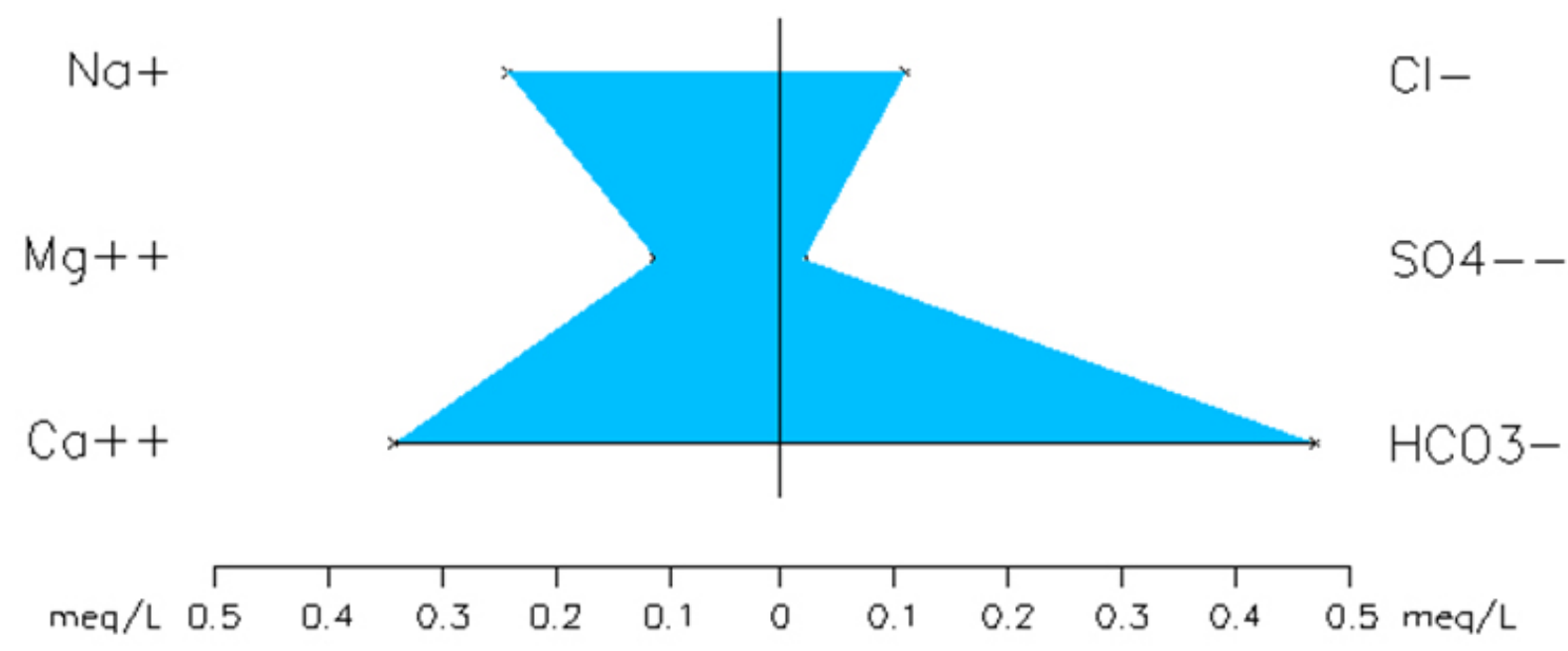

Figura 5: Diagrama de Stiff da amostra do piezômetro PCH01.

Figure 5: Stiff diagram for piezometer PCHO1 sample.

A origem continental desta amostra também é evidência pelas relações iônicas (Tabela 6). Segundo Custódio e Llamas (2001), águas continentais tendem a apresentar relação $\mathrm{rMg} / \mathrm{rCa}$

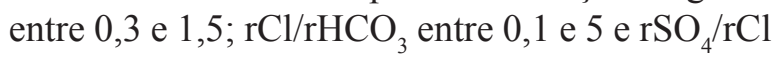
entre 0,2 e 0,4 .

Tabela 6: Relações iônicas para a amostra do piezômetro PCH01

Table 6: Ionic ratio to piezometer PCH01 sample

\begin{tabular}{|c|c|}
\hline \multicolumn{2}{|c|}{ Relação iônica } \\
\hline $\mathrm{rMg} / \mathrm{Ca}$ & 0,33 \\
\hline $\mathrm{rSO}_{4} / \mathrm{rCl}$ & 0,19 \\
\hline $\mathrm{rCl} / \mathrm{rHCO}_{3}$ & 0,23 \\
\hline
\end{tabular}

Como será discutido posteriormente, as equipotenciais geradas para a área mostram um fluxo de leste para oeste, ou seja, do mar em direção ao continente, entretanto a baixa salinidade das águas, e a origem continental comprovada, corrobora a ideia de que existe um divisor de águas entre o mar e a área de estudo conforme será proposto adiante.

Para a verificação do comportamento do aquífero livre quanto ao fluxo vertical, foram utilizados dois instrumentos com profundidades diferentes que se comportaram como câmaras independentes (multiníveis). As medidas foram efetuadas no piezômetro PCH01 com 1,87 metros de profundidade e no poço de monitoramento PMCH01 com 2,96 metros de profundidade, distantes 0,20 metros um do outro. Ambos os instrumentos apresentaram nível d'água a 1,24 metros de profundidade às $08: 55 \mathrm{~h}$ do dia 05.10.2009. Uma única medida não permite que se tirem conclusões a respeito do fluxo vertical, entretanto, é de se esperar que não haja fluxo 
ascendente no aquífero (gradiente hidráulico vertical significativo) haja vista que aquífero é livre, homogêneo e raso.

Foram realizadas medições de nível d'água nos dias 25 e 26.04 .2009 no intervalo de 14:40 a 15:45 h. Analisando os dados da tábua de maré da Diretoria de Hidrografia e Navegação da Marinha do Brasil, estação de Barra de Paranaguá - Canal da Galheta, verificou-se que as medições de nível d'água coincidiram com as maiores elevações de maré nos dias dos experimentos (25.04.2009: 1,60 $\mathrm{m}$ de altura às 15:49 e 26.04.2009: 1,50 metros de maré às 16:30). A potenciometria gerada a partir das cargas hidráulicas e dos levantamentos das cotas dos piezômetros para o dia 25.04.2009 (maré alta) mostra um fluxo na direção norte mais próximo ao mar, e na direção noroeste mais próximo ao Rio Perequê, como pode ser visualizado na FIGURA 6.

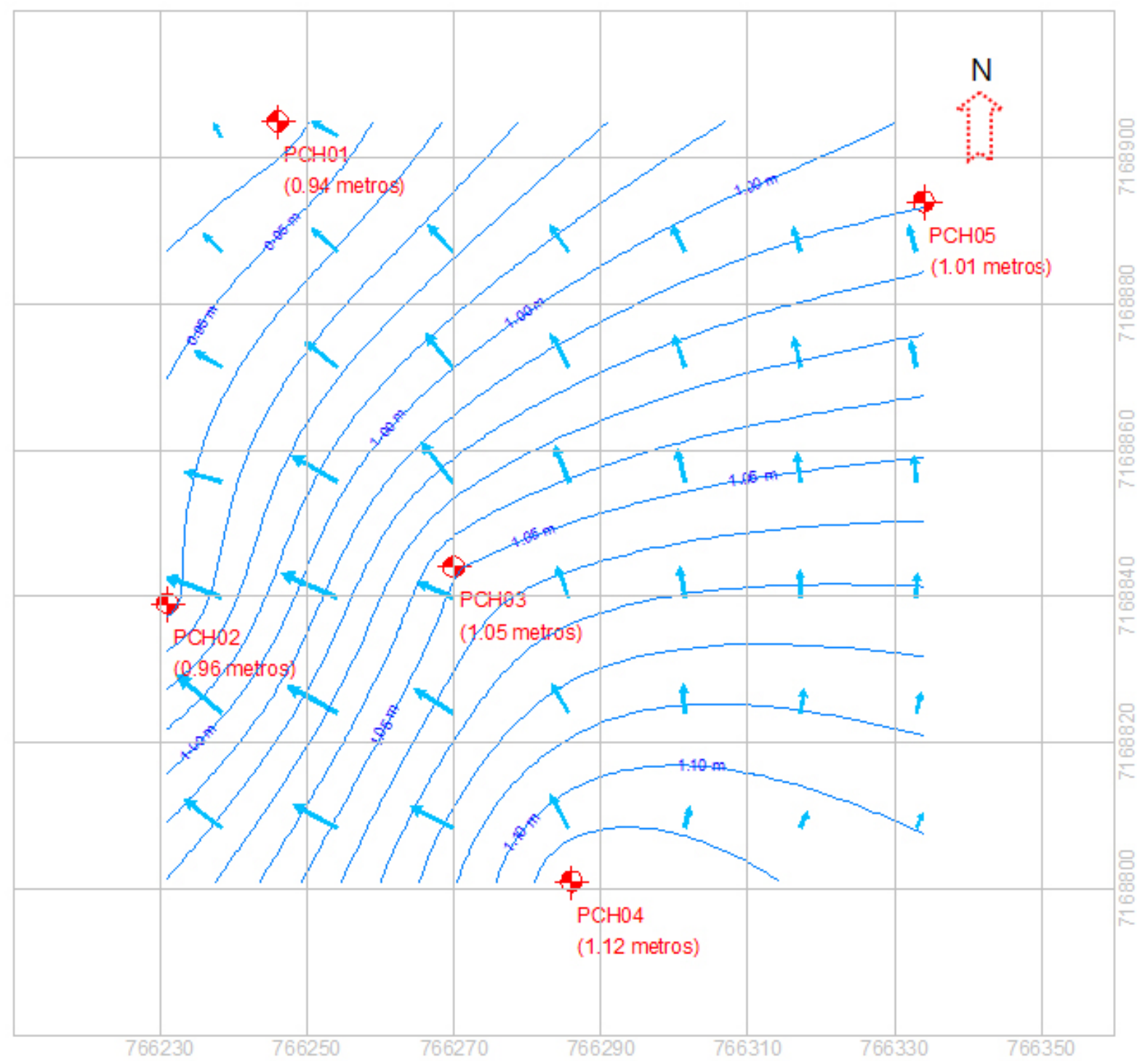

Figura 6: Mapa potenciométrico da área de estudo de acordo com as medições de nível d'água realizadas em 25.04.2009.

Figure 6: Potenciometric map of the study area according to water level measures in 04. 25.2009. 
Levando-se em consideração apenas a hipótese de que a maré influenciaria a inversão do fluxo subterrâneo (para o continente), em 05.10.2009, foram realizados dois experimentos considerando o nível mais baixo da maré $(0,10 \mathrm{~m}$ de altura por volta de 09:00 h) e o nível mais alto $(1,50 \mathrm{~m}$ de altura por volta de 15:38 h) como é mostrado nas Figuras 7 e 8.

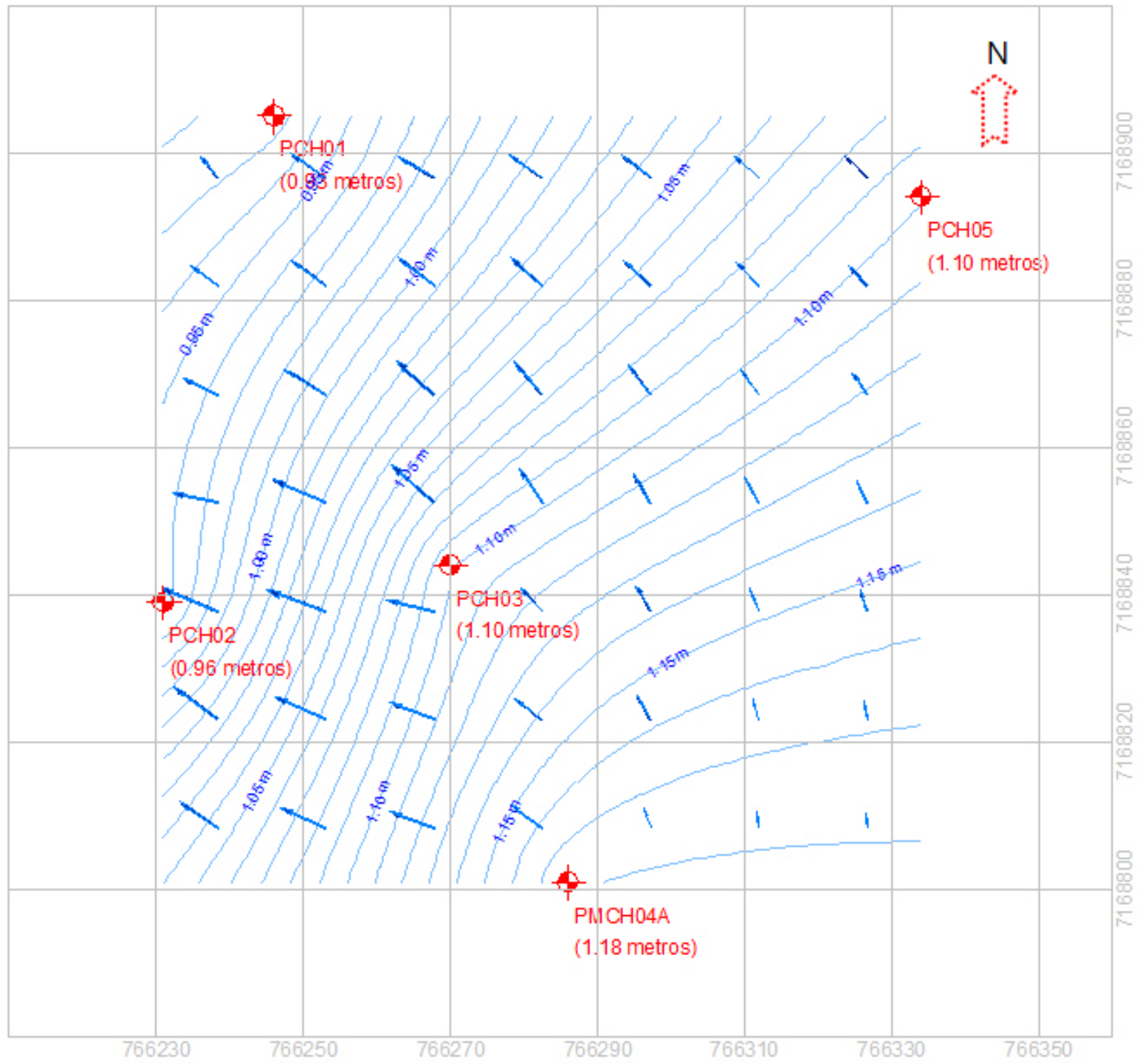

Figura 7: Mapa potenciométrico da área de estudo em 05.10.2009 por volta das 09:00h (Maré Baixa) Figure 7: Potenciometric map of the study area in 10.05.2009, around 09:00 a.m. (Low Tidal) 


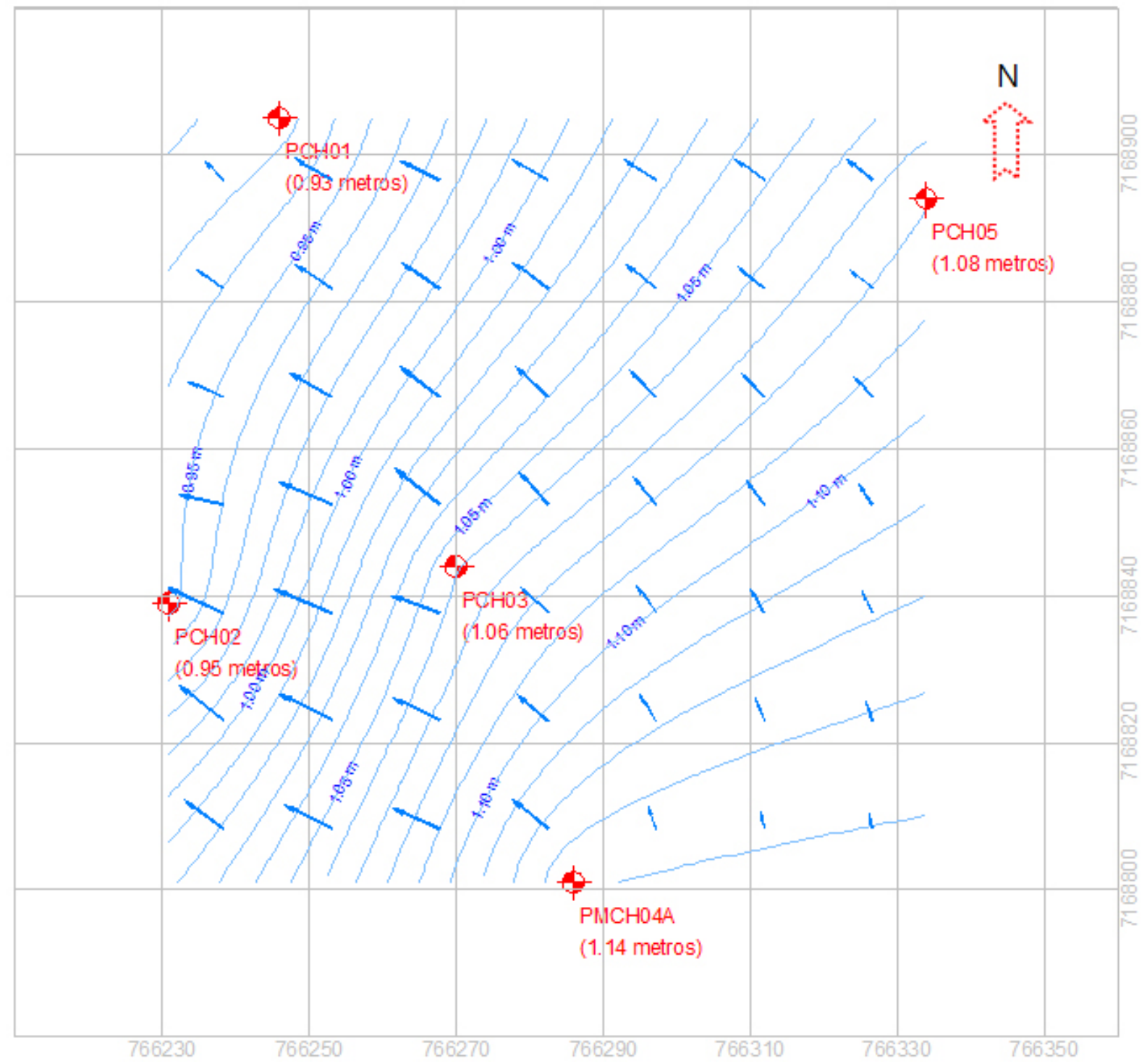

Figura 8: Mapa potenciométrico da área de estudo em 05.10.2009 por volta das 15:40h (Maré Alta)

Figure 8: Potenciometric map of the study area in 10.05.2009, around 3:40 p.m. (High Tidal)

Como pode ser visto nas Figuras 7 e 8, as linhas de fluxo apresentaram pequenas alterações quando comparadas as condições de maré baixa e maré alta. Entretanto, o ponto de destaque observado é que, em ambas as condições, o aquífero livre apresenta direção de fluxo SE-NW em sentido ao continente, sendo o ponto de descarga preferencial o canal do Rio Perequê, ou seja, o mangue.

Durante a maré baixa, o nível d'água observado nos piezômetros é maior que o nível do mar e, portanto, tem de haver um divisor de águas subterrâneas entre a área de estudo e a linha de costa. Na maré alta, o nível d'água do aquífero livre é menor que o nível do mar, podendo haver um fluxo sentido mar-continente.

Com o objetivo de compreender melhor o comportamento hidrogeológico da área de estudo, principalmente quanto à influência da maré no comportamento do fluxo subterrâneo, optouse por um monitoramento sistemático durante um período de trinta e quatro dias corridos, com monitoramento do nível d'água em intervalos de cinco minutos. O período de monitoramento foi de 06.10.2009 a 09.11.2009 e abrangeu todas as fases da Lua. Os dados obtidos foram comparados com os dados da tábua de marés da estação de Barra do Paranaguá - Canal de Galheta, obtidos junto à Diretoria de Hidrografia e Navegação da Marinha do Brasil.

Tal como pode ser observado na Figura 9, os dados mostram que a maré tem pouca ou quase nenhuma influência na variação do nível d'água do aquífero livre, sendo que os picos de elevação do nível d'água coincidem com picos de chuva. O aquífero livre é formado exclusivamente por areias de granulação fina a média com elevada porosidade efetiva, o que faz com que a água de chuva, ao chegar ao solo, seja imediatamente infiltrada, recarregando e elevando o nível d'água do aquífero. 


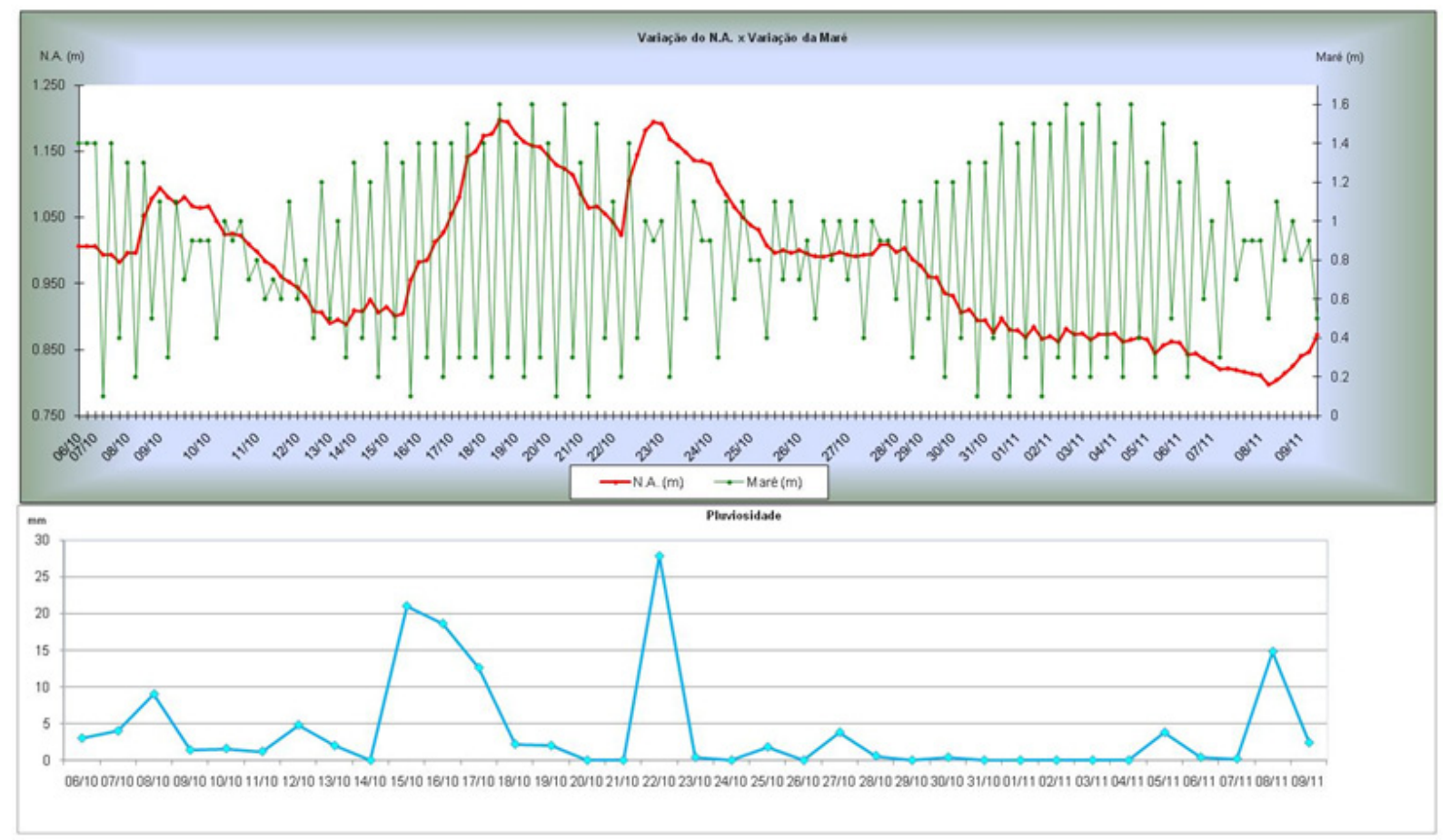

Figura 9: Gráfico comparativo entre a variação do nível d'água do aquífero livre e da maré

Figure 9: Comparative graphic between aquifer and tidal water level data.

Analisando os níveis d'água monitorados, observa-se que não há grandes diferenças quando comparados os carregamento máximos e mínimos de maré, conforme mostrado na Figura 10. Para os carregamentos máximos e mínimos de maré para o período monitorado, nota-se que a variação do nível d'água não ultrapassou 0,059 metros para um carregamento de maré de 1,60 metros em 20.10.2009.

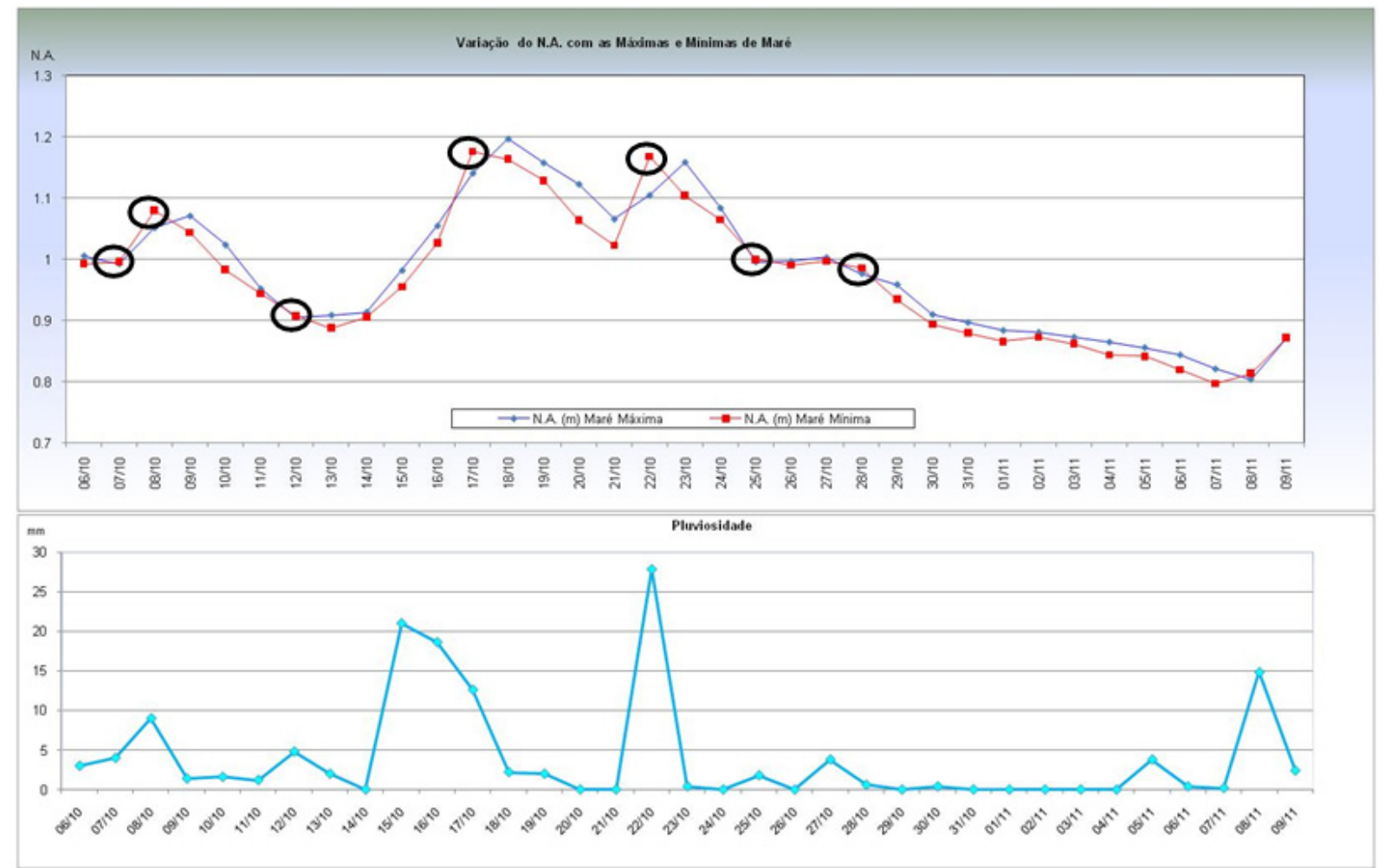

Figura 10: Gráfico dos níveis d'água observados para as marés máximas e mínimas durante o período monitorado

Figure 10: Observed water level graphic for high and low tidals during the monitored period 
Nos períodos em que não há incidência significativa de chuva que possa alterar o regime de recarga subterrânea, por exemplo, entre os dias 29.10.2009 e 07.11.2009, podemos avaliar com maior precisão a influência da maré no comportamento subterrâneo. Neste período, a diferença máxima de nível d'água observada foi de 0,024 metros para um carregamento de maré de 1,60 metros em 02.11.2009, comprovando assim que a maré não influência de forma significativa o comportamento subterrâneo do aquífero livre na área de estudo.

Os pontos anômalos marcados com um círculo preto na FIGURA 10 correspondem a situações onde o nível d'água da maré mínima elevase acima do nível d'água da maré baixa, como resultado da alta taxa de infiltração da água de chuva no aquífero livre.

A alta porosidade da área estudada, total (39 a $45 \%$ ) e efetiva (30 a 38\%), juntamente com um conjunto de fatores como insolação, pouca profundidade do aquífero e evapotranspiração, influenciam diretamente a temperatura da água do aquífero livre, conforme pode ser observado na Figura 11.

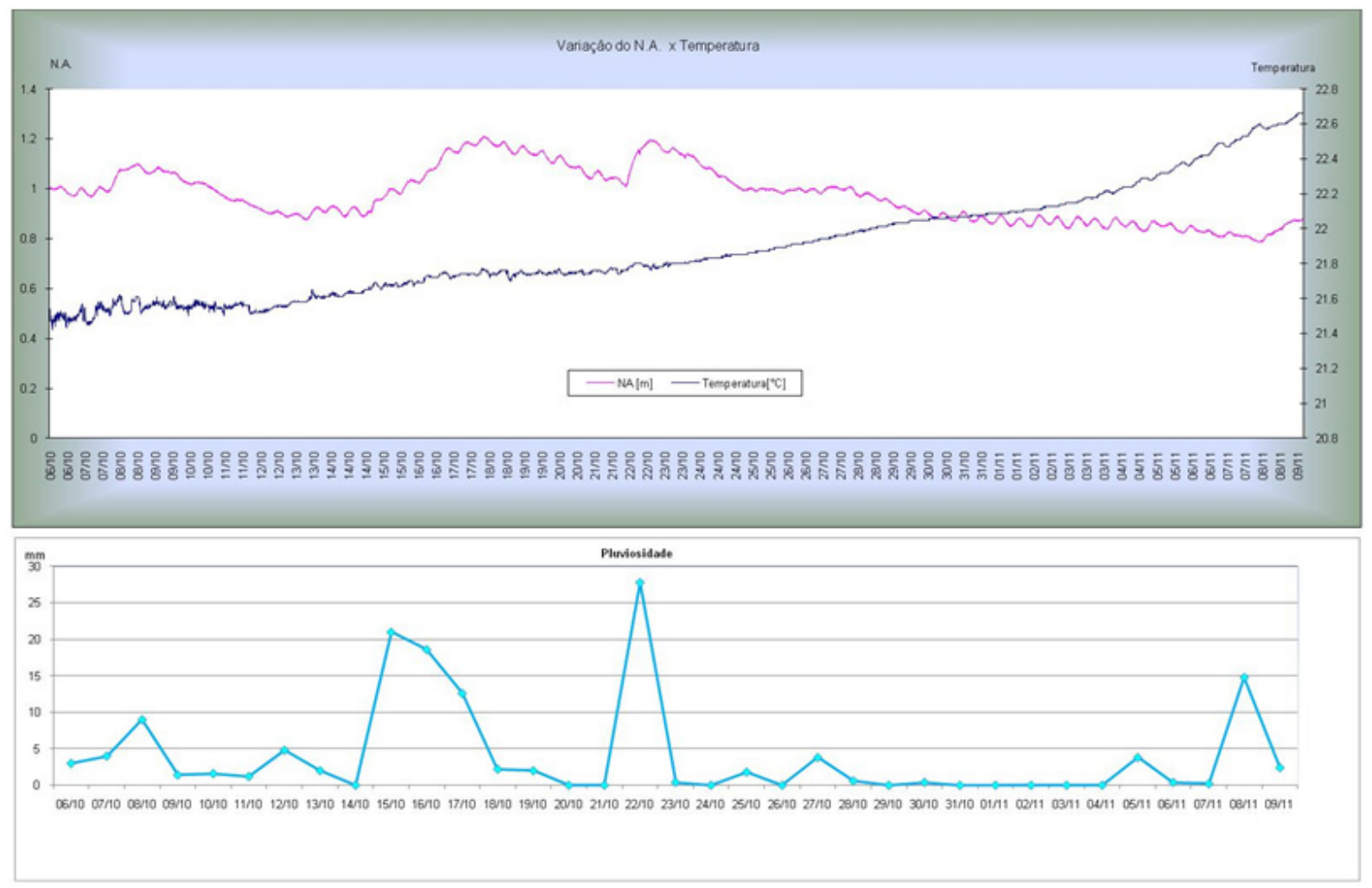

Figura 11: Gráfico comparativo entre a variação da temperatura e do nível d'água do aquífero livre

Figure 11: Comparative graphic between temperature variation and unconfined aquifer water level

Como pode ser visto na Figura 11, quase que imediatamente ao cessar as chuvas, a temperatura começar a se elevar ao seu padrão natural, que acredita-se ser em torno de $27^{\circ} \mathrm{C}$. Essa foi a temperatura medida em 25.04.2009 (Tabela 4), mês este que apresentou o terceiro menor índice pluviométrico do ano de 2009.

\section{CONCLUSÕES}

A localidade de Pontal do Sul apresenta um aquífero granular livre, altamente vulnerável devido a sua pouca profundidade e a sua composição estritamente de areia fina a média com elevada porosidade, tanto total como efetiva, que proporciona uma elevada e rápida taxa de recarga.

Este aquífero livre é constituído de águas de origem continental, bicarbonatadas-cálcicassódicas, com baixa condutividade elétrica e temperatura aproximada de $27^{\circ} \mathrm{C}$ em períodos de menor índice pluviométricos. $\mathrm{O}$ ambiente subterrâneo é oxidante o $\mathrm{pH}$ varia de neutro a levemente ácido.

O fluxo subterrâneo na área de estudo ocorre predominantemente na direção NE-SW em sentido ao continente, com a descarga do aquífero livre para o canal do Rio Perequê (mangue). A 
comparação entre os níveis de marés e os níveis d'água monitorados nos piezômetros nos sugere que exista um divisor de águas entre a área de estudo e a linha de mar durante as marés mais baixas, enquanto que, durante as marés altas, exista um fluxo do mar em direção ao continente, embora a análise química realizada evidencie águas estritamente continentais.

O nível d'água do aquífero livre tem baixa ou quase nenhuma influência das variações de maré e está diretamente relacionado a fatores climáticos, predominantemente a chuva. Os baixos valores de condutividade elétrica apresentados também indicam uma baixa interferência da maré.

A condutividade hidráulica encontrada para aquífero livre é da ordem de $10^{-3} \mathrm{~cm} / \mathrm{s}$ a $10^{-2}$ $\mathrm{cm} / \mathrm{s}$, portanto dentro dos valores apresentados na literatura para o litotipo encontrado na área de estudo.

Pontal do Sul ainda não é uma localidade onde a exploração do recurso hídrico subterrâneo é utilizada em larga escala e sua superfície territorial é carente de empreendimentos que coloque em risco a qualidade da água subterrânea. Nesse sentido, é importante que se desenvolva um maior número de pesquisas hidrogeológicas na localidade, com o intuito de se prover o desenvolvimento da região, porém com segurança para gerar e criar diretrizes objetivando uma melhor gestão dos recursos hídricos subterrâneos e, com isso, preservar esse recurso essencial às futuras gerações, sem comprometer o seu desenvolvimento econômico.

\section{REFERÊNCIAS BIBLIOGRÁFICAS}

ASTM - American Society for Testing and Materials. Disponível em: <www.astm.org/ Standard >. Acesso em: 22 ago. 2008. 21:42.

CHANG, H. K.; CARRIER, N. D. W. Programa de aquisição e tratamento automatizado de testes de slug. Unesp - Fundunesp. Registro INPI \# 000332760, 2000.

CUSTÓDIO, E.; LLAMAS M. R. Hidrologia subterrânea. Barcelona: Ediciones Omega, S.A., 2001. 185 p.

DHN - Diretoria de Hidrografia e Navegação. Disponível em: <https://www.mar.mil.br/dhn/ dhn/index.html >. Acesso em: 15 jun. 2009. 20:42.

FEITOSA, F. A.C.; MANOEL FILHO, J.; FEITOSA, E.C.; DEMÉTRIO, J.G.A. Hidrogeologia: conceitos e aplicações. Rio de Janeiro: CPRM, LABHID, 2008. 812 p.

HANNA Instruments Brasil. Disponível em: $<$ www.hannabrasil.com/catalogos/>. Acesso em: 03 maio 2009, 08:43.

HVORSLEV, M. J. Time lag and soil permeability in ground water observations. Bul. Army Corps of Engineers Waterway Experimentation Station, US. n. 36, 1951.

NIELSEN, M. D. Environmental site characterization and ground-water monitoring. $2^{\text {nd }}$ ed. Boca Raton, Florida: CRC Press, 2006. 517 p.
ONG, J.; AGUDA, N.; JARAULA, C.; MATEO, Z.; PASCUA, C.; FORONDA, J. Revista Science Diliman. Quezon City, Philippines, v. 12, n. 2, p. 33-44, julho-dezembro. 2000.

PEDE, M.A.Z.Caracterização da condutividade hidráulica do embasamento cristalino alterado saturado na região metropolitana de São Paulo. Dissertação de Mestrado. Rio Claro: Instituto de Geociências e Ciências Exatas da Unesp, Campus de Rio Claro, 2004. $11 \mathrm{f}$.

RACHWAL, M. F. G.; CURCIO, G. R. Revista Scientia Forestalis. Piracicaba, n. 59, p. 153-163, jun. 2001.

SHEPHERD, R.G. Correlations of permeability and grain size. Groundwater, v. 5, n. 27, p. 633638, 1989.

SOUZA, R. T.; Aspectos fundamentais à compreensão da hidrogeologia costeira numa área de Pontal do Sul - PR. Dissertação (Dissertação de Mestrado em Geologia). Curitiba: Departamento de Geologia, Universidade Federal do Paraná, 2010. $43 \mathrm{f}$.

SURESH BABU, D. S.; SAHAI, A. K.; NOENBERG, M. A.; MARONE, E. Hydraulic response of a tidally forced coastal aquifer, Pontal do Paraná, Brazil. Hidrogeology Journal, Heidelberg, v. 16, n. 7, p. 1427-1439, nov. 2008. 